\title{
Fostering EFL/ESL Students' State Motivation: The Role of Teacher-Student Rapport
}

\author{
Yanzhi Meng* \\ School of Foreign Languages, Xinxiang Medical University, Xinxiang, China
}

It is maintained that one of the significant determining issues of success is motivation, and enhancing EFL/ESL students' motivation is dominant in cultivating their learning in the classroom. Moreover, teachers are reflected as the most noteworthy figure of any scholastic organization and the positive rapport between students and teachers is significant for learners' state motivation. In line with the investigations of teacher-student rapport, principles from positive psychology (PP), and motivational theories such as self-determination and rhetorical/relational goal theory, the present theoretical review seeks this type of relationship and its effects on learners' motivation. Student-teacher rapport results in progressive practices for learners, as well as superior classroom involvement, and motivation. Subsequently, the helpfulness of findings for teachers, learners, materials developers, and teacher trainers are conferred.

\section{OPEN ACCESS}

Edited by:

Ali Derakhshan,

Golestan University, Iran

Reviewed by:

Liu Wei,

Xinyang Normal University, China Reza Bagheri Nevisi, University of Qom, Iran

*Correspondence:

Yanzhi Meng yanzhi_meng01@126.com

Specialty section:

This article was submitted to

Educational Psychology,

a section of the journal

Frontiers in Psychology

Received: 07 August 2021 Accepted: 17 August 2021 Published: 13 September 2021

Citation:

Meng Y (2021) Fostering EFL/ESL Students' State Motivation: The Role

of Teacher-Student Rapport.

Front. Psychol. 12:754797.

doi: 10.3389/fpsyg.2021.754797
Keywords: EFL/ESL students, students' state motivation, teacher-student rapport, self-determination, rhetorical goal theory

\section{INTRODUCTION}

Assuming a significant part in learners' education and academic achievement, as shown by research, motivation tends to become weaker and weaker as learners become older and transfer to higher grades and education. A particularly significant stage is the change from primary to secondary education (Murphy and Alexander, 2000; Yeung et al., 2011). In order to capture the role played in the social climate of the class, it is crucial to comprehend the distinctions and longitudinal changes in learners' motivation (Opdenakker et al., 2012). As stated by Corpus et al. (2009), learners' commitment and motivation can be positively influenced by educators who showed inspiring performance. Teachers are likewise key figures, who, especially through class contacts, shape learners' education (Pianta et al., 2012). For instance, researchers have examined learners' motivation as both a state- and a trait-like factor. As described by Christophel (1990), state motivation is a situational concept that alludes to the work put in the direction of a specific assignment domain at a specific point in time. As asserted by (as cited in Goldman et al., 2017), trait motivation is a somewhat steady paradigm that alludes to the general drive of learners toward learning and education. In light of its solid relationship with compelling teaching practices like nonverbal promptness, lucidity, affinity seeking, affirmation, and humor, state motivation is frequently favored by many researchers (Comadena et al., 2007; Goodboy and Myers, 2008; Kerssen-Griep and Witt, 2012).

Language learning is an activity that mainly happens in classes; notwithstanding, few know that motivation develops in these conditions or the ordinary associations between learners and teachers (Ushioda, 2013). There is a need for a study that carries out narrower experimental attention, and which can reveal insight into motivation as it arises in specific exercises and arranged 
connections since L2 motivation research has generally emphasized learning procedures at an overall level (Ushioda, 2016). The class climate adds to the improvement of learners' motivation and commitment to learning, and further develops learners' scholarly execution (Velayutham and Aldridge, 2013). As a component of the class climate, the teacher-student relationship has been confirmed to be of imperative significance for learners' education (Hughes et al., 2012). Indeed, learners and teachers who arrange a learning relationship in a learning environment to deliver desired learning results are at the focal stage of all instructive frameworks (Pishghadam et al., 2019; Xie and Derakhshan, 2021).

Besides, the acknowledgment that a psychological portrayal of a relationship with an educator can establish a wellspring of motivation is significant since language learning happens at the micro-level of societal action, and includes interactive connections with others inside repeating contexts of use (Henry and Thorsen, 2018). The study of motivation in L2 education goes back to several years ago as some scholars (e.g., Bravo et al., 2017; Busari, 2018; Djaya et al., 2018; Wijnen et al., 2018) pinpointed that motivation is viewed as one of the main persuasive and prominent issues in a person's accomplishment for learning both second or foreign language.

Furthermore, positive teacher-student connections fill in as an outside wellspring of motivational change, thereby adding to dynamic learning practices (Ma et al., 2017). One's motivation and accomplishment in a course might be vigorously impacted by the educator's performance and the students' cooperative activities, as some may have encountered (Passini et al., 2015; Wei et al., 2015). According to social motivation theorists, learners with social help from educators will develop solid motivational convictions that will advance dynamic learning commitment and great execution (Furrer and Skinner, 2003). Indeed, a steady teacher-student rapport can even halfway counter the regularly noticed decrease in learners' self-governing motivation as time goes by (Lapointe et al., 2005). The presumption that the nature of instructor-learner rapport assumes a focal part in advancing motivation and expanding learning returns to speculations from interpersonal psychology, which sees an individual's conduct with regards to conditional causality and reciprocal impacts (Strack and Horowitz, 2012).

Studies on the significance of high-quality teacher-student connections have gotten expanding consideration in 20 years (Roorda et al., 2011). High-quality teacher-student connections give a steady establishment to long-haul learners' education (Hamre and Pianta, 2001). Learners will perform better scholastically and experience more prominent school commitment at the point when they feel their teachers like them (Wang and Eccles, 2013). Numerous inquiries have discovered that learners with close educator rapport are bound to encounter scholastic interest, commitment, accomplishment, self-efficacy, and motivation as opposed to learners with more far-off relations (Sakiz et al., 2012; Tosto et al., 2016).

Learners are bound to miss their classes when they do not feel upheld by their educators (Demir et al., 2019). They are motivated to go to their classes at the point when they have more noteworthy degrees of teacher-learner rapport or trust their educators at higher levels. Learners have more opportunities to develop rapport with their educators when they go to class consistently, and this might advance ceaseless participation. Positive teacher-student connections help learners' transferring to school (Cheung, 2019). When learners were involved in school and had confidence in their capacities, they acclimated it better. Furthermore, learners had more significant levels of motivation when they cooperated with their educators all the more regularly (Liu and Chiang, 2019).

The relations between educators and learners influence learning conditions as many pieces of research have certainly focused on educator cooperation with learners as a recognizable factor to start critical base and motivation for the instructing and learning cycle, to rouse learners' motivation to take a functioning part in the learning climate, to show the teachers' accommodation, and to build a positive class climate that will help learners' education (Bouras and Keskes, 2014).

In light of the fact that learners and teachers are similarly accountable for the fruitful realization of the educational and learning cycles, the rapport between the two is significant (Delos Reyes and Torio, 2020). Thus, they should cooperate to assemble positive learning conditions. By utilizing social practices that are related to learners' positive encounters, educators trigger the foundation of such conditions (Bolkan et al., 2016). Since learning incorporates social, mental, and emotional connections, it could be said that learning includes something beyond simple openness to data. Along these lines, successful education is normally realized inside a positive teacher-learner relationship setting (Strachan, 2020). In spite of the fact that teacher-learner rapport is an indispensable part of any learning situation, the way toward making and keeping a positive rapport is a challenging task for some accomplished educators (Strachan, 2020). Hence, it is extremely fundamental to apprehend the cycles of fundamental successful teacher-learner connections.

Besides, language learning is an intrinsically friendly interaction, considerably more than other scholarly subjects (Mercer and Gkonou, 2020), so the nature of the teacher-learner connection is very significant in the L2 setting (Wang and Derakhshan, 2021). Generally, the language information is educated and utilized adequately through various methods of correspondence (Frymier et al., 2019). Accordingly, there is a great necessity for connections with individual conversationalists (i.e., the educator or friends). Depending on how well educators and learners interact with one another, their instructing and learning encounters can either improve or get ruined, respectively.

Rapport further develops various class domains; explicitly, it advances motivation, criticism, learners' education, correspondence, and obviously the educator's well-being. Learners, who often communicate with a teacher, are more fulfilled and are less inclined to drop out (Wasley, 2006). It is at that point that educators should place more accentuation in building positive rapport in the English as a Foreign Language class as it will certainly be a pivot (Dyrenforth, 2014).

Learners' motivation is a key to numerous compelling teaching practices and their definitive impact (positive or negative) on learners' education results (Frymier, 2016). Two 
issues have obstructed researchers in testing and appreciating motivational clarifications of educators' correspondence manners. The functional cross-over between the proportions of motivation and emotional learning is the first issue (Goldman et al., 2017). The second issue is the oversimplified perspective on motivation as a paradigm changing just in amount and not in value (Goldman et al., 2017).

The self-determination theory (Deci and Ryan, 2012) and rhetorical/relational goal theory are powerful clarifications of motivation theories that resolve this issue by offering a complete hypothetical structure for understanding educators' correspondence manners (Frymier, 2016). Correspondence analysts must start to accept the self-determination theory to see how educators meet learners' fundamental requirements and how the satisfaction of these necessities works with learners' practices and, eventually, teaching (Bolkan et al., 2016).

Educator promptness, affirmation, and affinity seeking work with positive instructor-learner connections, which, therefore, works with need fulfillment (Frymier, 2016). In particular, when learners feel associated with the instructor by the expansion of these conducts, they are bound to have their relatedness needs fulfilled. Additionally, rhetorical conducts like instructor lucidity and pertinence would almost certainly establish learning conditions that serve to fulfill the necessities of skill and selfsufficiency, opening the entryway for learners to foster their inherent motivation for education.

Upon reviewing the collected works on correspondence and motivation, Frymier (2016) contended that the motivation hypothesis, particularly SDT, gave the best clarification to the connection between instructors' correspondence conduct and learners' education. She contended that compelling educators' correspondence conducts like instantaneousness, lucidity, affirmation, and affinity seeking are likely to be associated with fulfilling learners' requirements for relatedness, skill, and independence, thereby, in a roundabout way, impacts intrinsic motivation.

As stated by Wentzel et al. (2010), a few pieces of research find that learners who foster positive associations with educators are emphatically propelled to seek scholarly greatness. By approvals corresponding to the learner out in the open, to such an extent that the learner who is publicly praised frequently becomes and remains profoundly intrigued by coursework and performs better, educators help to motivate learners' education in the class (as cited in Liu and Chiang, 2019). While literature corresponds that learner-educator rapport is fundamentally identified with learners' motivations, the direction of this connection relies upon the specific communication style (Liu and Chiang, 2019).

Positive teacher-student rapport is strong expediters of a widespread sort of appropriate learner-related results such as engagement, accomplishment, motivation, and confidence (Davis, 2003; Wendt and Courduff, 2018; Derakhshan et al., 2019; Havik and Westergård, 2020; Derakhshan, 2021; Pishghadam et al., 2021). Mainly, a high-quality teacher-student rapport heightens learner motivation; on the contrary, a poor relationship between them is echoed as a failure on students' motivation in the procedure of learning (Wubbels and Brekelmans, 2005; Opdenakker et al., 2012). Outstandingly, longitudinal investigation demonstrated that students who face a route of connectedness with an educator similarly preserve motivation (Hamre and Pianta, 2005). In addition, Joe et al. (2017) stated that teachers' educational provision of learners, and their encouragement of reciprocal self-esteem in the classroom, influence learners' motivation to a great extent.

Regarding EFL/ESL students' state motivation investigation, the impacts of constructive teacher-student rapport have not been studied earlier, and accordingly, it becomes a pertinent topic for this review. Moreover, the main lacuna in this theoretical review based on the researcher's knowledge is that although teacher-learners rapport has been much under investigation in general learning, they are not taken into account from the EFL/ESL perspective (Hagenauer and Volet, 2014). As a result, thanks to the integral relational aspect of language teaching (Mercer and Dörnyei, 2020) and grounded on the current development and flourishing of PP in SLA emphasizing that constructive emotions (Wang et al., 2021), between teacher and learners, must be taken into consideration in L2 teaching and learning and clarifying how and why teacher-student rapport is related to learner motivation has been an enduring trial.

\section{THEORIES OF MOTIVATION}

The self-determination theory and rhetorical/relational goal theory are two of the most generally utilized theoretical methods clarifying the significance of high-quality instructor-learner connections, as a segment of the interpersonal psychology area.

\section{Self-Determination Theory}

The self-determination theory (Deci and Ryan, 2008) clarifies the connection between educator-learner connections and great school revision or scholarly motivation through the satisfaction of three essential mental requirements: the requirement relatedness, the requirement for skill, and the requirement for self-governance. Learners' education and motivation for accomplishment, which is connected to learning, will be expanded if an instructor meets these three fundamental requirements of learners' by showing responsibility, guaranteeing clear structures, and reinforcing the self-governance of learners (Roorda et al., 2011). Self-determination theorists utilize the attachment theory to characterize "commitment" as an emotional part of educator-learner connections. Accordingly, the essential requirement for attachment is firmly connected to the idea of wellbeing (Roorda et al., 2011). The nature of educatorlearner connections is thus estimated by the satisfaction of the previously mentioned three essential requirements, which fortify one another and accommodate ideal and healthy development (Bakadorova and Raufelder, 2018).

In particular, SDT envisages that intrinsic motivation relies upon three fundamental mental requirements: the requirement for autonomy, the requirement for competence, and the requirement for relatedness (Deci and Ryan, 2008). Being the apparent wellspring of one's own behavior is known as autonomy which is positively correlated with teacher success and consequently learners' motivation (Derakhshan et al., 2020). People feel autonomous when they disguise 
their conduct as a declaration of their very own free will (Ryan and Deci, 2002). Feeling compelling in one's continuous collaborations in a social climate is known as competence. People experience competence whenever they experience testing opportunities that permit them to relay their actual capabilities (Deci and Ryan, 2008). Perceiving an association with others is known as relatedness. Individuals need to have secure associations with others for relatedness to be fulfilled. These significant interpersonal associations might be developed with the educator and/or different learners in the learning setting. Thus, relatedness assumes a fundamental part in encouraging commitment, particularly when initial intrinsic, or inborn, motivation is deficient (Ryan and Deci, 2009). Relatedness is experienced when people foster a feeling of belongingness with their companions, or with others for whom they have high regard (e.g., Moller et al., 2010; Beachboard et al., 2011).

All the more explicitly, when learners experience relatedness with instructors, they get more prominent joy from learning exercises in a school subject and are bound to see themselves as more skilled in this subject (Deci and Ryan, 2000). Participating in communications and keeping up with connections is subject to interpersonal motives, from a socio-motivational viewpoint. Certainly, individuals can be variously motivated to connect. The two fundamental elements of interpersonal motives are agency and communion. The former identifies with attention on self-interest, accomplishment, and individual impact, and the latter identifies with an emphasis on enthusiasm and social cooperation (Horowitz et al., 2006).

\section{The Rhetorical/Relational Goal Theory}

Proposed by (as cited in Zheng, 2021) to perceive how the cycle of instructional correspondence works, the rhetorical/relational goal theory is a hypothesis in the domain of instructional correspondence. In light of this theory, teachers and learners in the class have rhetorical and relational objectives that they wish to accomplish. The significant obligation is the educators' as they are relied upon to oversee both relational and rhetorical necessities simultaneously through their manner decisions to satisfy the class's needs; thus, ideal learning can occur when these objectives are attained and learners' needs are fulfilled.

It is important to mention that the rhetorical and relational practices of educators fill various roles. For example, teachers utilize rhetorical educational correspondence practices to advance compelling educating and influence convictions, perspectives, and practices of students in the class through molding their planned instructional messages (Beebe and Mottet, 2009). Then again, as stated by Myers (2008), educators utilize relational instructional correspondence practices to trigger the development of a commonly formed proficient relationship and rapport with their learners. Certainly, to achieve good results in any learning setting, educators should utilize a combination of rhetorical and relational practices (Myers et al., 2018).

\section{TEACHER-STUDENT RAPPORT}

An amicable educator-learner relationship identified with delight, association, regard, and common trust is known as rapport (Delos Reyes and Torio, 2020). Being significantly relationship-based, it is a relational bond during the education cycle (Frisby and Housley Gaffney, 2015). As stated by Frisby et al. (2016), rapport, in contrast to other educational correspondence factors, is less examined. However, since rapport is an inevitable part of instruction as well as the fact that learners' learning starts from it, it is perhaps the most important component of educational correspondence. Rapport can be built by educators in the class by advancing free expression, respecting learners' mentalities, giving fitting criticism, utilizing humor, displaying eagerness in learners' education, and being delicate and enthusiastic (Weimer, 2010).

\section{IMPLICATIONS AND FUTURE DIRECTIONS}

The current review of literature has some implications for instructive situations. Consequently, it can be of importance to several participants in the educational setting, together with teachers, teacher trainers, materials developers, and those who are responsible for employing teachers, and those preparing teacher professional development programs.

The current review can be instructive and beneficial for language educators as they ought to attend workshops that are intended to emphasize the relational part of the class climate to learn explicit techniques which will work with positive associations with learners (Terry, 2006). Given the significance of social practices and the impression of the connections on learners' education, educator training in building connections to accomplish positive results is probably an advantageous endeavor.

Based on this theoretical review, it is confirmed that teacherstudent rapport not only boosted the rudimentary teaching development but also supported the growth of students' motivation on the way to success. It is the responsibility of the teachers to build students' motivation and inspire them to create positive approaches toward learning and their behavior is thoroughly correlated with student motivation and presentation and teacher support through interpersonal relationships is interconnected to students' subject-related motivational aspects (Yildirim, 2012). The more, the students face teacher support, the greater their degree of motivation in the route of language education which is concerning their social-emotional regulation (McElhaney et al., 2008).

From an informative perspective, the present review sheds light on the importance of student-teacher rapport as it inspires and motivates the educator to articulate the new teaching methods and review their ideas to construct a positive relationship with students to boost motivation that results in their engagement and achievement. It is worth noting that teachers who have a constructive relationship with their learners generate a classroom atmosphere that improves learning and runs into learners' emotional and scholastic desires. Positive student-teacher rapport provides the groundwork for efficacious 
alteration to the educational situation for learners at the inception of their formal teaching. Learners, who reflect that their educator does not support them in the classroom, have low attentiveness and they are less motivated and active in the learning setting (Tyler and Boelter, 2008). In the same way, when educators collaborate with learners and have a respectful and sympathetic attitude toward learners, their stress diminishes and they can fully focus on their lessons with the high motivation that is congruent with Mercer and Dörnyei (2020), who evinced that the L2 Motivational Self System creates a brilliant route of attentiveness and engagement. Moreover, teachers should develop their interpersonal behavior through cultivating their proximity, i.e., their physical and emotional confidence to learners and such performances will generate a constructive reaction from learners toward their educators, firmly functioning to surge learners' pleasure by articulating confidence, and being supportive (Beebe and Mottet, 2009). Accordingly, by adopting interactional manners, and cooperating with learners not only in the class but also before and after the class, educators are supposed to accomplish higher motivation leading to educational and emotional upshots.

As for students, this line of review can be of importance as it increases their consciousness and awareness of the fact that an educational method is a co-built event whose attainment is not wholly the responsibility of educators. Indeed, learners are correspondingly dominant in providing an abundant way for their achievement to happen. They try to begin a sociable rapport with their teachers, and this closeness enhances their confidence and motivation. When learners are acquainted with their dynamic role in the learning process, they show more motivation and commitment in their performances.

The next participants who can use this review are teacher trainers who can nurture the knowledge of novice educators

\section{REFERENCES}

Bakadorova, O., and Raufelder, D. (2018). The essential role of the teacher-student relationship in students' need satisfaction during adolescence. J. Appl. Dev. Psychol. 58, 57-65. doi: 10.1016/j.appdev.2018. 08.004

Beachboard, M. R., Beachboard, J. C., Li, W., and Adkison, S. R. (2011). Cohorts and relatedness: self- determination theory as an explanation of how learning communities affect educational outcomes. Res. High. Educ. 52, 853-874. doi: $10.1007 / \mathrm{s} 11162-011-9221-8$

Beebe, S. A., and Mottet, T. P. (2009). "Students and teachers: communication in the classroom," in 21st-Century Communication: A Reference Handbook, ed W. F. Eadie (Thousand Oaks, CA: Sage), 349-357.

Bolkan, S., Goodboy, A. K., and Kelsey, D. M. (2016). Instructor clarity and student motivation: academic performance as a product of students' ability and motivation to process instructional material. Commun. Educ. 65, 129-148. doi: 10.1080/03634523.2015.1079329

Bouras, H., and Keskes, S. (2014). "Teacher-learner rapport impact on EFL learners' motivation," in International Conference on Social Sciences and Humanities. Proceedings of SOCIOINT14- International Conference on Social Sciences and Humanities (Istanbul), 546-554.

Bravo, J. C., Intriago, E. A., Holguín, J. V., Garzon, G. M., and Arcia, L. O. (2017). Motivation and autonomy in learning English as foreign language: a case study of Ecuadorian college students. Engl. Lang. Teach. 10, 100-113. doi: $10.5539 /$ elt.v10n2p100 regarding teacher-student rapport as they can propose workshops, conferences, and other preparation developments in which educational, emotional, and interpersonal features of education are correspondingly taught. For better upshots, governments need to fill the lacuna between government and language school organizations. Appropriate supervision and psychoanalysis should be provided for students at diverse levels of their learning development to motivate them in language learning. More in detail, teacher mentors can provide a chance for educators to discern the implication and practice of teacherstudent rapport in the achievement of their careers. Additionally, materials developers can take advantage of this type of research in a way to design courses that consider the teacher-student rapport as a core component of education that emphasizes rapport in the process of accomplishing tasks and in such a way that educators can focus on their clearness, rapport with students, and authority.

In conclusion, portfolios, philosophical papers, and thinkaloud procedures can be employed as well to perceive the mental procedures that teachers and learners come across. Likewise, the interpersonal rapport of teachers and learners should be studied from the points of view of both teachers and learners. Further research can be utilized on the opinions of administrators, teacher trainers, too. In addition, enthusiastic scholars are recommended to scrutinize the influence of educators' experience level, academic experiences, age, and gender in this domain.

\section{AUTHOR CONTRIBUTIONS}

The author confirms being the sole contributor of this work and has approved it for publication.
Busari, A. O. (2018). Motivation, stress, anxiety and emotions as predictors of academic boredom among degree students of national teachers' Institute Osogbo, Osun State, Nigeria. World Sci. News 112, 165-179.

Cheung, C. S. (2019). Parents' involvement and adolescents' school adjustment: teacher-student relationships as a mechanism of change. Sch. Psychol. 34, 350-362. doi: $10.1037 /$ spq0000288

Christophel, D. (1990). The relationship among teacher immediacy behaviors, student motivation, and learning. Commun. Educ. 39, 323-340.

Comadena, M. E., Hunt, S. K., and Simonds, C. J. (2007). The effects of teacher clarity, nonverbal immediacy, and caring on student motivation, affective and cognitive learning. Commun. Res. Rep. 24, 241-248. doi: $10.1080 / 08824090701446617$

Corpus, J. H., McClintic-Gilbert, M., and Hayenga, A. (2009). Within-year changes in children's intrinsic and extrinsic motivational orientations: contextual predictors and academic outcomes. Contemp. Educ. Psychol. 34, 154-166. doi: 10.1016/j.cedpsych.2009.01.001

Davis, H. A. (2003). Conceptualizing the role and influence of student-teacher relationships on children's social and cognitive development. Educ. Psychol. 38, 207-234. doi: 10.1207/S15326985EP3804_2

Deci, E. L., and Ryan, R. M. (2000). The what and why of goal pursuits: human needs and the self-determination of behavior. Psychol. Inq. 11, 227-268. doi: 10.1207/S15327965PLI1104_01

Deci, E. L., and Ryan, R. M. (2008). Self-determination theory: a macrotheory of human motivation, development, and health. Can. Psychol. Psychol. 49, 182-185. doi: 10.1037/a0012801 
Deci, E. L., and Ryan, R. M. (2012). "Motivation, personality, and development within embedded social contexts: an overview of self-determination theory," in The Oxford Handbook of Human Motivation, ed R. M. Ryan (Oxford: Oxford University Press Inc.), 85-107.

Delos Reyes, R. D. G., and Torio, V. A. G. (2020). The relationship of expert teacher-learner rapport and learner autonomy in the CVIF-dynamic learning program. Asia Pac. Educ. Res. 20, 1-11. doi: 10.1007/s40299-020-00532-y

Demir, M., Burton, S., and Dunbar, N. (2019). Professor-student rapport and perceived autonomy support as predictors of course and student outcomes. Teach. Psychol. 46, 22-33. doi: 10.1177/0098628318816132

Derakhshan, A. (2021). The predictability of Turkman students' academic engagement through Persian language teachers' nonverbal immediacy and credibility. J. Teach. Pers. Speak. Other Lang. 10, 3-26. doi: $10.30479 /$ jtpsol.2021.14654.1506

Derakhshan, A., Coombe, C., Arabmofrad, A., and Taghizadeh, M. (2020). Investigating the effects of English language teachers' professional identity and autonomy in their success. Issues Lang. Teach. 9, 1-28. doi: 10.22054/ilt.2020.52263.496

Derakhshan, A., Saeidi, M., and Beheshti, F. (2019). The interplay between Iranian EFL teachers' conceptions of intelligence, care, feedback, and students' stroke. IUP J. Engl. Stud. 14, 81-98.

Djaya, A. A., Imran, C.h., and Sahabuddin, R. (2018). The influence of entrepreneurship learning and individual commitment toward achievement motivation and its impact on the interest of business establishment for vocational high school students in Makassar, Indonesia. J. Bus. Manag. $20,10-14$.

Dyrenforth, T. (2014). Classroom Success Through Rapport-Building. West Point, NY: Master Teacher Program, United States Military Academy.

Frisby, B. N., and Housley Gaffney, A. L. (2015). Understanding the role of instructor rapport in the college classroom. Commun. Res. Rep. 32, 340-346. doi: 10.1080/08824096.2015.1089847

Frisby, B. N., Slone, A. R., and Bengu, E. (2016). Rapport,motivation, participation, and perceptions of learning in U.S. and Turkish student classrooms: a replication and cultural comparison. Commun. Educ. 66, 183-195. doi: 10.1080/03634523.2016.1208259

Frymier, A. B. (2016). "Students' motivation to learn," in Handbooks of Communication Science: Communication and Learning, ed P. L. Witt (Berlin: De Gruyter Mouton), 378-396.

Frymier, A. B., Goldman, Z. W., and Claus, C. J. (2019). Why nonverbal immediacy matters: a motivation explanation. Commun. Q. 67, 526-539. doi: 10.1080/01463373.2019.1668442

Furrer, C., and Skinner, E. (2003). Sense of relatedness as a factor in childrens academic engagement and performance. J. Educ. Psychol. 95, 148-162. doi: 10.1037/0022-0663.95.1.148

Goldman, Z. W., Goodboy, A. K., and Weber, K. (2017). College students' psychological needs and intrinsic motivation to learn: an examination of self-determination theory. Commun. Q. 65, 167-191. doi: $10.1080 / 01463373.2016 .1215338$

Goodboy, A. K., and Myers, S. A. (2008). The effect of teacher confirmation on student communication and learning outcomes. Commun. Educ. 57, 153-179. doi: $10.1080 / 03634520701787777$

Hagenauer, G., and Volet, S. E. (2014). Teacher-student relationship at university: an important yet under-researched field. Oxf. Rev. Educ. 40, 370-388. doi: $10.1080 / 03054985.2014 .921613$

Hamre, B. K., and Pianta, R. C. (2001). Early teacher-child relationships and the trajectory of children's school outcomes through eighth grade. Child Dev. 72, 625-638. doi: 10.1111/1467-8624.00301

Hamre, B. K., and Pianta, R. C. (2005). Can instructional and emotional support in the first-grade classroom make a difference for children at risk of school failure? Child Dev. 76, 949-967. doi: 10.1111/j.1467-8624.2005.00889.x

Havik, T., and Westergård, E. (2020). Do teachers matter? students' perceptions of classroom interactions and student engagement. Scand. J. Educ. Res. 64, 488-507. doi: 10.1080/00313831.2019.1577754

Henry, A., and Thorsen, C. (2018). Teacher-student relationships and L2 motivation. Mod. Lang. J. 102, 218-241. doi: 10.1111/modl.12446

Horowitz, L. M., Wilson, K. R., Turan, B., Zolotsev, P., Constantino, M. J., and Henderson, L. (2006). How interpersonal motives clarify the meaning of interpersonal behavior: a revised circumflex model. Pers. Soc. Psychol. Rev. 10, 67-86. doi: 10.1207/s15327957pspr1001_4

Hughes, J. N., Wu, J. Y., Kwok, O. M., Villarreal, V., and Johnson, A. Y. (2012). Indirect effects of child reports of teacher-student relationship on achievement. J. Educ. Psychol. 104, 350-365. doi: 10.1037/a0026339

Joe, H.-K., Hiver, P., and Al-Hoorie, A. H. (2017). Classroom social climate, self-determined motivation, willingness to communicate, and achievement: a study of structural relationships in instructed second language settings. Learn. Individ. Differ. 53, 133-144. doi: 10.1016/j.lindif.2016.11.005

Kerssen-Griep, J., and Witt, P. L. (2012). Instructional feedback II: how do instructor immediacy cues and face work tactics interact to predict student motivation and fairness perceptions? Commun. Stud. 63, 498-517. doi: 10.1080/10510974.2011.632660

Lapointe, J. M., Legault, F., and Batiste, S. J. (2005). Teacher interpersonal behavior and adolescents' motivation in mathematics: a comparison of learning disabled, average, and talented students. Int. J. Educ. Res. 43, 39-54. doi: 10.1016/j.ijer.2006.03.005

Liu, R., and Chiang, Y. (2019). Who is more motivated to learn? The roles of family background and teacher-student interaction in motivating student learning. The Journal of Chinese Sociology 6, 1-17. doi: 10.1186/s40711-019-0095-Z

Ma, L., Du, X., Hau, K.-T., and Liu, J. (2017). The association between teacher-student relationship and academic achievement in Chinese EFL context: a serial multiple mediation model. Educ. Psychol. 38, 687-707. doi: 10.1080/01443410.2017.1412400

McElhaney, K. B., Antonishak, J., and Allen, J. P. (2008). They like me, they like me not: popularity and adolescents' perceptions of acceptance. Child Dev. 79, 493-513. doi: 10.1111/j.1467-8624.2008.01153.x

Mercer, S., and Dörnyei, Z. (2020). Engaging Language Learners in Contemporary Classrooms. Cambridge: Cambridge University Press.

Mercer, S., and Gkonou, C. (2020). "Relationships and good language teachers," in Lessons From Good Language Teachers, eds C. Griffiths and Z. Tajeddin (Cambridge: Cambridge University Press), 164-174.

Moller, A. C., Deci, E. L., and Elliot, A. J. (2010). Person-level relatedness and the incremental value of relating. Pers. Soc. Psychol. Bull. 36,754-767. doi: $10.1177 / 0146167210371622$

Murphy, P. K., and Alexander, P. A. (2000). A motivated exploration of motivation terminology. Contemp. Educ. Psychol. 25, 3-53. doi: 10.1006/ceps.1999.1019

Myers, S. A. (2008). "Classroom student-teacher interaction," in The International Encyclopedia of Communication, ed W. Donsbach (Malden, MA: Blackwell), 514-520.

Myers, S. A., Baker, J. P., Barone, H., Kromka, S. M., and Pitts, S. (2018) Using rhetorical/relational goal theory to examine college students' impressions of their instructors. Commun. Res. Rep. 35, 131-140. doi: 10.1080/08824096.2017.1406848

Opdenakker, M. C., Maulana, R., and den Brok, P. (2012). Teacher-student interpersonal relationships and academic motivation within one school year: developmental changes and linkage. Sch. Effect. Sch. Improv. 23, 95-119. doi: 10.1080/09243453.2011.619198

Passini, S., Molinari, L., and Speltini, G. (2015). A validation of the questionnaire on teacher interaction in Italian secondary school students: the effect of positive relations on motivation and academic achievement. Soc. Psychol. Educ. 18 547-559. doi: 10.1007/s11218-015-9300-3

Pianta, R. C., Hamre, B. K., and Allen, J. P. (2012). "Teacher-student relationships and engagement: conceptualizing, measuring, and improving the capacity of classroom interactions," in Handbook of Research on Student Engagement, eds S. L. Christenson, A. L. Reschly, and C. Wylie (Boston, MA: Springer), 365-386.

Pishghadam, R., Derakhshan, A., and Zhaleh, K. (2019). The interplay of teacher success, credibility, and stroke with respect to EFL students' willingness to attend classes. Pol. Psychol. Bull. 50, 284-292. doi: 10.24425/ppb.2019.131001

Pishghadam, R., Derakhshan, A., Zhaleh, K., and Al-Obaydi, L. H. (2021). Students' willingness to attend EFL classes with respect to teachers' credibility, stroke, and success: a cross-cultural study of Iranian and Iraqi students' perceptions. Curr. Psychol. 40, 1-15. doi: 10.1007/s12144-021-01738-z

Roorda, D. L., Koomen, H. M. Y., Spilt, J. L., and Oort, F. J. (2011). The influence of affective teacher-student relationships on students' school engagement and achievement: a meta-analytic approach. Rev. Educ. Res. 81, 493-529. doi: $10.3102 / 0034654311421793$ 
Ryan, R. M., and Deci, E. L. (2002). "Overview of self-determination theory: an organismic dialectical perspective," in Handbook of Self-Determination Research, eds E. L. Deci and R. M. Ryan (Rochester, NY: University of Rochester Press), 3-33.

Ryan, R. M., and Deci, E. L. (2009). "Promoting self-determined school engagement," in Handbook of Motivation at School, eds K. R.Wentzel and A. Wigfield (New York, NY: Routledge), 171-195.

Sakiz, G., Pape, S. J., and Hoy, A. W. (2012). Does perceived teacher affective support matter for middle school students in mathematics classrooms? J. Sch. Psychol. 50, 235-255. doi: 10.1016/j.jsp.2011.10.005

Strachan, S. L. (2020). The case for the caring instructor. Coll. Teach. 68, 53-56. doi: $10.1080 / 87567555.2019 .1711011$

Strack, S., and Horowitz, L. M. (2012). "Introduction," in Handbook of Interpersonal Psychology, ed L. M. Horowitz and S. Strack (https://www.google.com/search?sxsrf= ALeKk01WtjCt8Ss1cyRRdzQHzYzX1mAI5g:1629557247754\&q= Hoboken\&stick=H4sIAAAAAAAAAOPgE-LUz9U3MMotLypT4gAxK_ LMk7S0spOt9POL0hPzMqsSSzLz81A4VhmpiSmFpYlFJalFxYtY2T3yk_ KzU_N2sDICAC-vG35QAAAA\&sa=X\&sqi=2\&ved= 2ahUKEwiqh5LnrcLyAhWDppUCHSx4AFYQmxMoATAoegQIQhAD NJ: Wiley), 1-13.

Terry, M. (2006). The importance of interpersonal relations in adult literacy programs. Educ. Res. Q. 30, 31-44.

Tosto, M. G., Asbury, K., Mazzocco, M. M. M., Petrill, S. A., and Kovas, Y. (2016). From classroom environment to mathematics achievement: the mediating role of self-perceived ability and subject interest. Learn. Individ. Differ. 50, 260-269. doi: 10.1016/j.lindif.2016.07.009

Tyler, K. M., and Boelter, C. M. (2008). Linking black middle school students' perceptions of teachers' expectations to academic engagement and efficacy. Negro Educ. Rev. 59, 27-44.

Ushioda, E. (2013). "Motivation and ELT: looking ahead to the future," in International Perspectives on Motivation: Language Learning and Professional Challenges, ed E. Ushioda (Basingstoke: Palgrave Macmillan), 233-239.

Ushioda, E. (2016). Language learning motivation through a small lens: a research agenda. Lang. Teach. 49, 564-577. doi: 10.1017/S0261444816000173

Velayutham, S., and Aldridge, J. M. (2013). Influence of psychosocial classroom environment on students' motivation and self-regulation in science learning: a structural equation modeling approach. Res. Sci. Educ. 43, 507-527. doi: 10.1007/s11165-011-9273-y

Wang, M., and Eccles, J. S. (2013). School context, achievement motivation, and academic engagement: a longitudinal study of school engagement using a multidimensional perspective. Learn. Instr. 28, 12-23.

Wang, Y. L., and Derakhshan, A. (2021). Review of the book investigating dynamic relationships among individual difference variables in learning English as a foreign language in a virtual world, by M. Kruk. System 100:102531. doi: 10.1016/j.system.2021.102531

Wang, Y. L., Derakhshan, A., and Zhang, L. J. (2021). Researching and practicing positive psychology in second/foreign language learning and teaching: the past, current status and future directions. Front. Psychol. 12:731721. doi: 10.3389/fpsyg.2021. 731721
Wasley, P. (2006). Accreditor of education school drops controversial 'social justice' language. The Chronicle of Higher Education. Retrieved from: http:// chronicle

Wei, M., Zhou, Y., Barber, C., and Den Brok, P. (2015). Chinese students' perceptions of teacher-student interpersonal behavior and implications. System 55, 134-144. doi: 10.1016/j.system.2015.09.007

Weimer, M. (2010). Rapport: why having it makes a difference. Teach. Prof. 23, 2-9.

Wendt, J. L., and Courduff, J. (2018). The relationship between teacher immediacy, perceptions of learning, and computer-mediated graduate course outcomes among primarily Asian international students enrolled in an US university. Int J. Educ. Technol. High. Educ. 15, 1-15. doi: 10.1186/s41239-018-0115-0

Wentzel, K. R., Battle, A., Russell, S. L., and Looney, L. B. (2010). Social supports from teachers and peers as predictors of academic and social motivation. Contemp. Educ. Psychol. 35, 193-202. doi: 10.1016/j.cedpsych.2010.03.002

Wijnen, M., Loyens, S. M., Wijnia, L., Smeets, G., Kroeze, M. J., and Van der Molen, H. T. (2018). Is problem-based learning associated with students motivation? a quantitative and qualitative study. Learn. Environ. Res. 21, 173-193. doi: 10.1007/s10984-017-9246-9

Wubbels, T., and Brekelmans, M. (2005). Two decades of research on teacher-student relationships in class. Int. J. Educ. Res. 43, 6-24. doi: 10.1016/j.ijer.2006.03.003

Xie, F., and Derakhshan, A. (2021). A conceptual review of positive teacher interpersonal communication behaviors in the instructional context. Front. Psychol. 12:2623. doi: 10.3389/fpsyg.2021.708490

Yeung, A. S., Lau, S., and Nie, Y. (2011). Primary and secondary students motivation in learning English: grade and gender differences. Contemp. Educ. Psychol. 36, 246-256. doi: 10.1016/j.cedpsych.2011.03.001

Yildirim, S. (2012). Teacher support, motivation, learning strategy use and achievement: a multilevel mediation model. J. Exp. Educ. 80, 150-172. doi: 10.1080/00220973.2011.596855

Zheng, J. (2021). A functional review of research on clarity, immediacy, and credibility of teachers and their impacts on motivation and engagement of students. Front. Psychol. 12:712419. doi: 10.3389/fpsyg.2021.712419

Conflict of Interest: The author declares that the research was conducted in the absence of any commercial or financial relationships that could be construed as a potential conflict of interest.

Publisher's Note: All claims expressed in this article are solely those of the authors and do not necessarily represent those of their affiliated organizations, or those of the publisher, the editors and the reviewers. Any product that may be evaluated in this article, or claim that may be made by its manufacturer, is not guaranteed or endorsed by the publisher.

Copyright (0) 2021 Meng. This is an open-access article distributed under the terms of the Creative Commons Attribution License (CC BY). The use, distribution or reproduction in other forums is permitted, provided the original author(s) and the copyright owner(s) are credited and that the original publication in this journal is cited, in accordance with accepted academic practice. No use, distribution or reproduction is permitted which does not comply with these terms. 